\title{
Effects of electrophysical processing on the development of vine root roots
}

\author{
Abdurahim Berdishev ${ }^{1 *}$, Nuriddin Markaev ${ }^{1}$, and Jamol Hasanov ${ }^{2}$ \\ ${ }^{1}$ Tashkent Institute of Irrigation and Agricultural Mechanization Engineers, Tashkent, Uzbekistan \\ ${ }^{2}$ Grand electrical mechanical service, Kashkadarya, Uzbekistan
}

\begin{abstract}
The article discusses the possibilities of electrophysical methods to increase the efficiency of grape seedling cultivation and increase root development in seedlings by $95-97 \%$ when exposed to the electric field strength of $16.64 \mathrm{~V} / \mathrm{m}$ and exposure for 12.24 hours. The possibility is explained in practical and theoretical terms. However, experimental data and various electrotechnologies aimed at increasing the efficiency of root formation and development by $15-20 \%$ in grape cuttings treated for 12 and 24 hours at 16 and $64 \mathrm{~V} / \mathrm{m}$ of electric field strength are presented.
\end{abstract}

\section{Introduction}

The yield of future vineyards and the quality of the harvest often depend on the seedlings' quality. Although many biological and agro-technical measures are being taken to increase the productivity of various fruit trees and grape seedlings, some farms have low seedling yields, which hinders the establishment of grape plantations.

The current state of science is to direct these factors in the right direction by controlling them through the electrophysical effects of various stimuli, including different forms of electromagnetic field energy (electric field, electric current, magnetic field, electric discharge, electromagnetic waves, pulsed electromagnetic field), indicates the possibility of redirection.

The process of root formation in grape seedlings is a complex biological process that depends on internal and external factors. [2]

Various experiments and theoretical knowledge on the study of different effects of electromagnetic field energy on grape cuttings and seedlings and their use in the cultivation of grape seedlings were analyzed using internet materials, literature, and patent data.

\section{Methods}

The practical application of this energy-saving approach to the processing of materials belonging to the plant kingdom requires an in-depth study of the process of exposure of electromagnetic fields to materials, which in turn is one of the most pressing issues in solving energy-saving problems in agricultural production.

*Corresponding author: markayev88@Mail.ru 
In general, the motion of the electromagnetic field energy is represented by the Pointing vector

$$
\vec{\Pi}=[\vec{E} \cdot \vec{H}]
$$

The point vector represents the direction of motion of the energy again, propagating electromagnetic waves directed perpendicular to the electric field strength and magnetic field strength vectors.

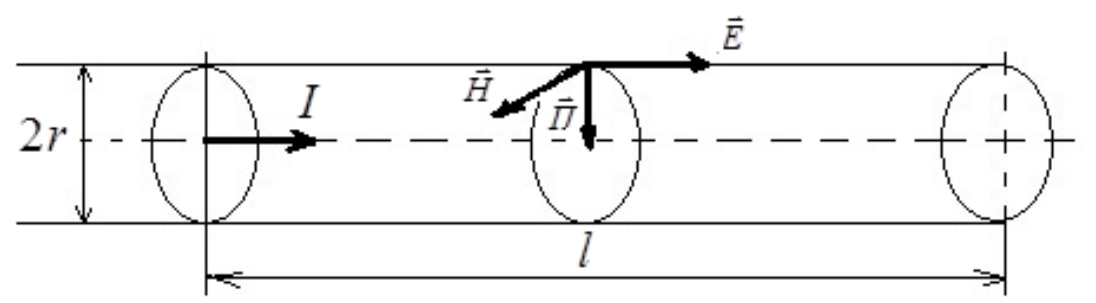

Fig. 1. The motion of energy in an alternating current conductor

In a unit of time, an electromagnetic wave directed (connected) to a material (body) of volume $\mathrm{V}$ of any finite surface $\mathrm{F}$ is partially absorbed by the body (technological environment), partially reflected, and partially transmitted. The energy A falling on an elementary surface (dA) can be expressed as follows.

$$
\bar{S}=-\oint_{A} \bar{\Pi} d \bar{A}=-\oint_{A}[\bar{E} \bar{H}] d \bar{A}
$$

The process of rooting of fruit trees and vines, the use of electromagnetic field energy for technological purposes in agronomics of agricultural crops, processing and storage of finished products have been proven to achieve new results. [1]

\section{Results and Discussion}

Researches of domestic and foreign scientists, including V.I.Michurina, A.M. Basov, I.I.Gunara, V.V.Pilyuginoy, P.P.Radchevsky, A.G.Kudryakov, B.R. Lazarinko, and I.F.Borodin found that electrophysical methods of exposure to biological objects, including materials belonging to the plant world, in some cases give not only quantitative but also qualitatively positive results, which other methods can achieve.

A.G.Kudryakov found that the process of rooting grape seedlings by processing grape seedlings using electricity can achieve good results when exposed to an electric field of 14 $\mathrm{V} / \mathrm{m}$ and 24 hours. [3] 


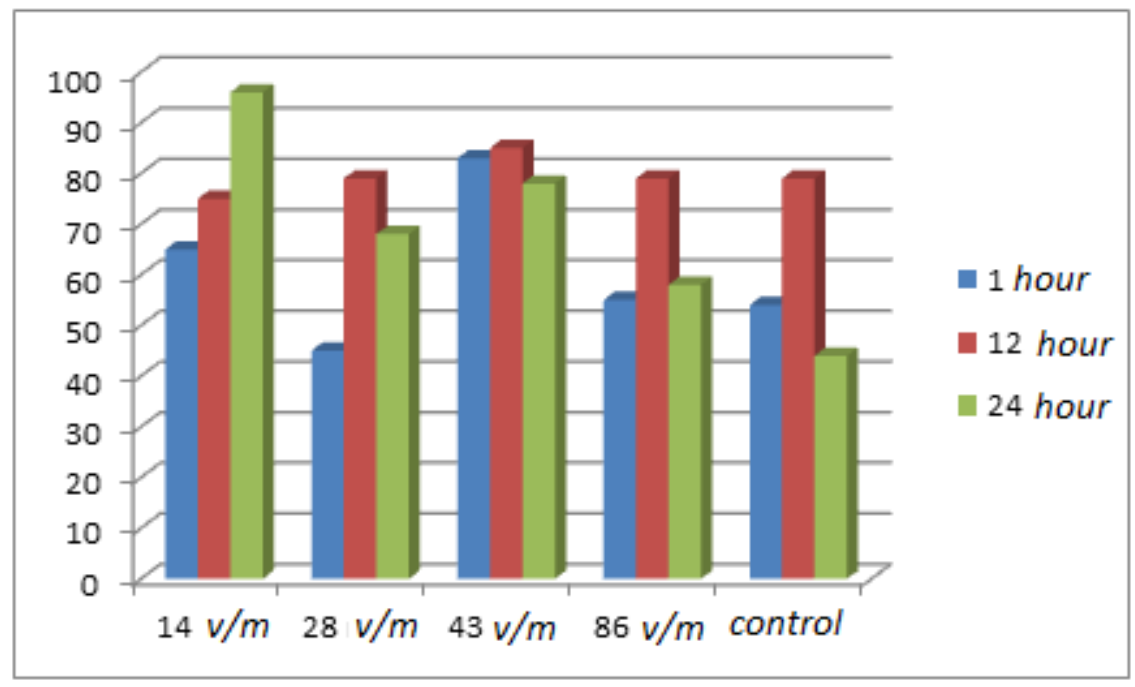

Fig. 2. The degree of root formation in grape cuttings depends on the electric field strength and processing time

The use of 50 Gts industrial frequency alternating current in electrophysical rooting methods in grape cuttings is recommended, and its transmission to the seedlings through the liquid was found to give high results. [3]

P.P.Radchevsky conducted two experiments in the spring. One control and one $0.01 \%$ heteroaxin solution were placed in the experiment, and four variants of one- and two-eyed grape cuttings were treated in a pulsed electromagnetic field. He found that when exposed to a pulsed electromagnetic field for 5-10 minutes, the rooting processes in grape cuttings are accelerated. Good results can be achieved through the effective use of these technologies [4].

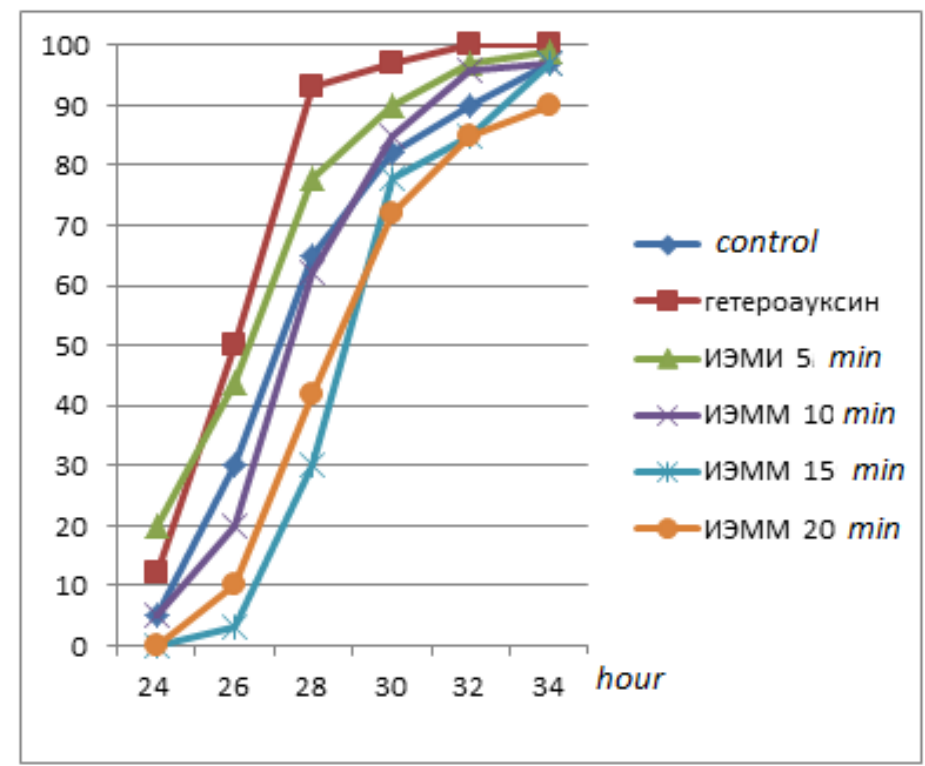

Fig. 3. Dynamics of root formation rate in two-eyed cuttings of grapes processed in a pulsed electromagnetic field. 
It should be noted that the process of root formation in grape cuttings treated in a pulsed electromagnetic field was 97.5-100. It was observed that the process of root formation in grape cuttings treated in a pulsed electromagnetic field for 5 minutes (IEMM-5 minutes) was accelerated by $7.5-15 \%$ compared to the control. [4]

Experiments and theoretical knowledge conducted by the analyzed scientists show that the rooting of fruit trees and vine seedlings may depend on a certain amount of harman active eyes.

Therefore, the inversion of electromagnetic fields into different forms of energy into biological and other energy types requires an in-depth study of the technical performance characteristics. Hence, the electromagnetic field is a form of matter that is interconnected as an energy supplier and is represented by a unit of electric and magnetic fields that form each other. [1]

The propagation of the electromagnetic field and its absorption by the environment are accompanied by the motion of the energy of the electromagnetic field, which is a unit of electric and magnetic fields. The electromagnetic field can exist (manifest) in various forms: electric field, electric current, magnetic field, electric discharge, electromagnetic waves, pulsed electromagnetic field, etc. Due to the fact that all types of electromagnetic energy are transformed into thermal, mechanical, chemical, biological, and other types of energy as a result of movement and conduction in the material environment, they can maximize their impact in solving problems of increasing energy efficiency in agricultural production. It is important to achieve efficiency.

A new methodological approach to solving the problem is to increase energy use efficiency by managing the flow of energy following the physical properties (conductive, semiconductor, insulator) and conditions (solid, liquid, gaseous) of the technological environment during the technological process. [2]

Technological efficiency is calculated only at the expense of energy absorbed by the material (technological environment).

The amount of energy absorbed by the technological environment depends on the electromagnetic field current indicators and the oscillation frequency (f), and the physical properties of the technological environment $\mu, \varepsilon, \mathrm{r}$. Therefore, the amount of energy absorbed by solid, liquid, gaseous, electrically conductive, dielectric, semiconductor objects (technological environment) placed in the flow of an electromagnetic field with the same parameters will be different and give different technological effects. [1]

This means that by using the various electrophysical effects of electromagnetic field energy, the rooting process in seedlings made from grape cuttings can be significantly enhanced. [2]

A small experiment was conducted, taking into account the theoretical knowledge studied. The experiment was performed in a common heated room. Two-eyed cuttings cut from my black currant variety were made from $20 \mathrm{~cm}$ in length. A total of 170 grape cuttings were used in the experiment. The number of grape cuttings processed using electricity was left for 160 and 10 for control. The experiment used an industrial frequency (50 Gts) alternating current with a voltage of $4,8,16,36 \mathrm{~V}$ and a processing time of $6,12,24,36$ hours. 


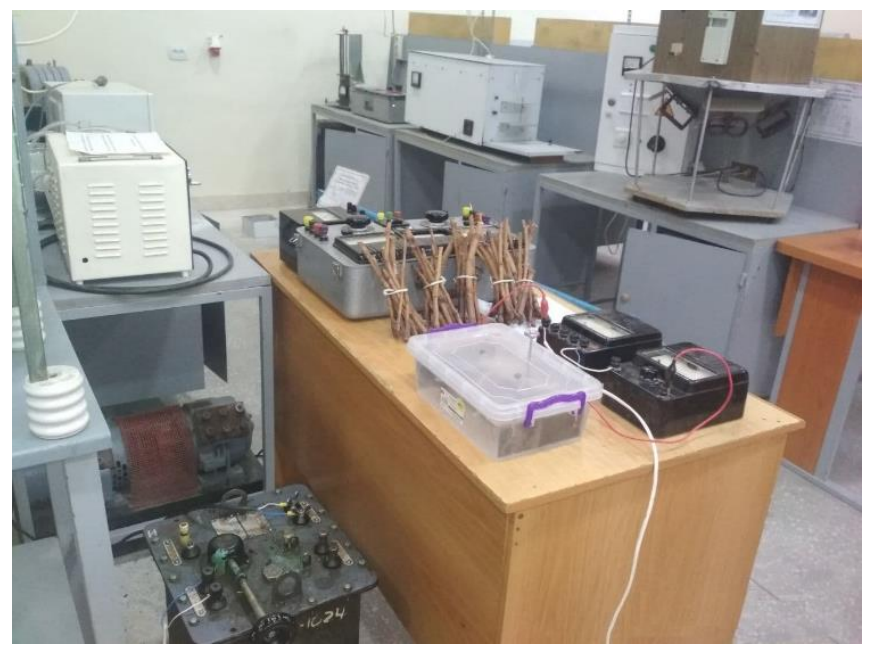

Fig. 4. The process of processing grape cuttings using electricity

The processed grape cuttings were stored separately in a container filled with water for 12 hours and planted in disposable containers.

The electric field strength was $16,32,64,144 \mathrm{~V} / \mathrm{m}$.

$$
\begin{gathered}
\varepsilon_{1}=\frac{U}{l}=\frac{4}{0,25}=16 B / \mu \varepsilon_{2}=\frac{U}{l}=\frac{8}{0,25}=32 B / \mu \quad \varepsilon_{3}=\frac{U}{l}=\frac{16}{0,25}=64 B / M \\
\varepsilon_{4}=\frac{U}{l}=\frac{36}{0,25}=144 B / \mathcal{M}
\end{gathered}
$$

All the grape cuttings were made from a single grape tree. The electrodes in the electrotechnical processing device were made of stainless steel; the distance between them was $25 \mathrm{~cm}$. 3.8-liter plastic containers were used for processing.

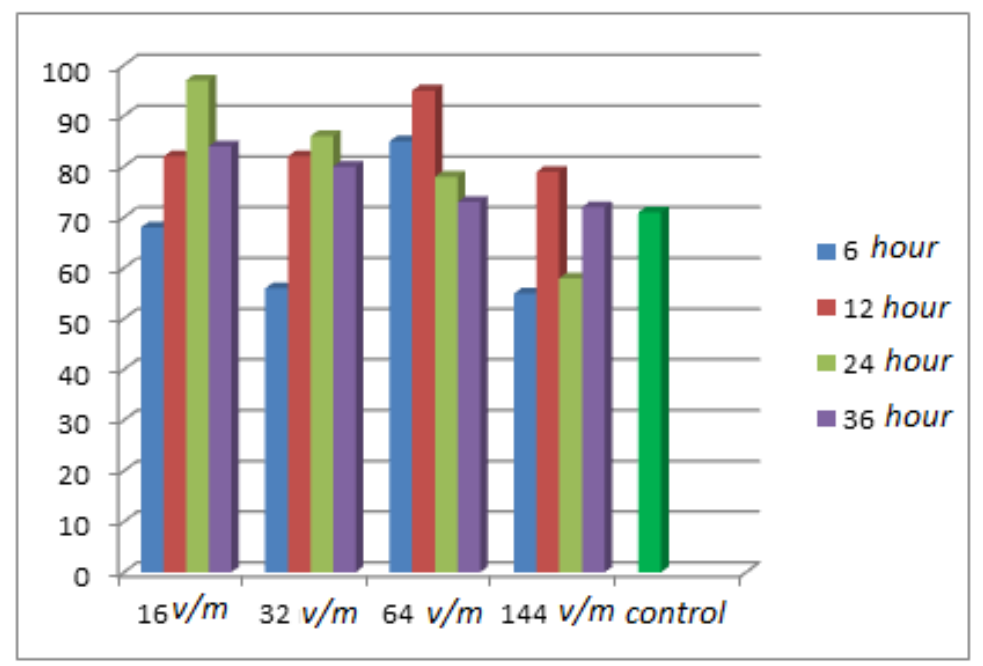

Fig. 5. Dependence of root development level on electric field strength and processing time in grape cuttings of black currant variety 
Root rooting processes by grape cuttings using electric current accounted for $95-97 \%$ of the root development process in cuttings at $16.64 \mathrm{~V} / \mathrm{m}$ electric field strength and $12.24 \mathrm{~h}$ exposure.

Compared to the control, at 16 and $64 \mathrm{~V} / \mathrm{m}$ electric field strength, root formation processes in grape cuttings treated for 12 and 24 hours were accelerated by $15-24 \%$.

As a result of small experiments and analyzes, it was found that grape seedlings are not affected by the active state when exposed to electricity, and plant tissues have active conductivity only at low levels of electric field strength [3].

Electrophysical treatment of grape seedlings significantly increases the process of root formation in grape cuttings, which can contribute to higher yields from seedlings grown using electrotechnological methods.

Despite the great prospects for using electrotechnological methods to control the vital processes of plant organisms belonging to the plant world, the application of these methods in the cultivation of seedlings from grape cuttings remains unexplored. The substantiation of technologies (electrophysical factors and energy parameters) for the cultivation of welldeveloped one- and two-year-old grape seedlings using electrotechnological methods without any damage to the body, variety, and roots is currently one of the most pressing issues for agriculture.

\section{Conclusion}

Such conclusions were reached by studying the research results conducted by researchers in Uzbekistan and abroad, the results of the analysis, and various experiments.

1. 1.Studies and various experimental tests have shown that the treatment of grape seedlings using electrophysical effects significantly accelerates the process of root formation in grape cuttings and can allow high yields from seedlings grown using these methods.

2. It is recommended to use an alternating current of $50 \mathrm{Gts}$ industrial frequency in the implementation of root formation processes in grape cuttings using electrotechnological methods. It was found that one of the most effective technologies is its liquid delivery to grape cuttings.

3. The process of root formation in grape cuttings with an electric field strength of $16.64 \mathrm{~V}$ $/ \mathrm{m}$ and exposure for 12.24 hours by electrotechnical processing of grape cuttings was 95-97\%.

4. Compared to the control, it was observed that the process of root formation in grape cuttings treated by electrotechnological methods was accelerated by $15-24 \%$.

5. Studies have shown that electrophysical treatment before planting agricultural products, i.e., grape cuttings, belonging to the plant world from different forms of electromagnetic field energy, can show positive results.

6. To study the effect of electromagnetic field energy on electrically conductive dielectric and insulating materials in liquid, solid and gaseous state, especially biological products, which can be used to increase the energy efficiency of agro-technical processes of agricultural production (fruit trees and grapes, apples, pomegranates) can be concluded that. 


\section{References}

1. Radjabov A., Eshpulatov N., Nabiyev S. Reserves for energy efficiency in processing and storage of fruit and vegetable products in the republic of Uzbekistan. International Journal of Electrical and Electronics Engineering Research (IJEEER). ISSN (P): 2250-155X; ISSN (E): 2278-943X; Vol. 8, Issue 4, p. 1-10 Dec (2018).

2. Yusubaliev A. Electric sorting in cotton growing: monograph / A. Yusubaliev; Tashkent Institute of Irrigation and Agricultural Mechanization Engineers. - 176 p. Novosibirsk: Akademizdat, (2019).

3. A.G. Kudryakov Stimulation of root formation of grape cuttings by an electric field: Authorization. Dissertation for Candidate of Technical Sciences, 23 p. Krasnodar, (1999).

4. P.R. Panteleevich. Influence of radix plus on the regenerative properties of moldova grape cuttings, depending on their length. Scientific journal KubSAU, No. 104 (10), (2014)

5. Taslimov A., Rakhimov F., L.Nematov, Markaev N., Bijanov A., Yunusov R. Economic load intervals for selecting $10 \mathrm{kV}$ cable cross sections for agricultural consumers. International Scientific Conference Construction Mechanics, Hydraulics and Water Resources Engineering CONMECHYDRO-2020 pp.19-26, October, (2020)

6. Bakhadirov I., Aslanova G., Tanarov R., Markaev N. Differentiated tariffs of electricity for the improvement of steelmaking Uzbekistan. International Scientific Conference Construction Mechanics, Hydraulics and Water Resources Engineering CONMECHYDRO-2020 pp.19-26, October, (2020).

7. Radjabov A., Ibragimov M., Eshpulatov N.M., Matchonov, O. Improving the energy performance of ozone generators used in agricultural ecology. Journal of Physics: Conference Series. Volume 1399, Issue 5, 5 055060. December (2019).

8. Ibragimov M., Eshpulatov N., Matchanov O. Electrical technology of moisture content reduction of industrial-grade cotton seeds. IOP Conference Series: Materials Science and Engineering. 883(1), 012135. (2020).

9. Sayfutdinov R.S., Mukhitdinov U.D., Eshpulatov N.M. Increasing reactivity of cotton celluloses for chemical processing. IOP Conference Series: Materials Science and Engineering. 883(1), 012133. (2020).

10. Bayzakova J.S., Abdildin N.K., Shynybay Zh.S., Chingenzhinova Zh.S., Berdyshev A.S., Eshpulatov N.M., Matchonov O.Q., Yusupov Sh.B. Methodology for conducting an optimization experiment for harvesting dry short-stalked grain crops. IOP Conf. Series: Earth and Environmental Science. 614 012118. (2020).

11. Ibragimov M., Eshpulatov N., Matchanov O. Substantiation of the optimal parameters by processing with electric contact methods to decrease the moisture content of technical seeds. IOP Conf. Series: Earth and Environmental Science. 614012018. (2020).

12. Radjabov A., Ibragimov M., Eshpulatov N. The study of the electrical conductivity of Apples and Grapes as an object of electrical processing. E3S Web of Conferences, 226, 00002. (2021),

13. Berdishev A. Taslimov A., Meliqo'ziyev B, A. Bijanov. Reliability indicators of 10 $\mathrm{kV}$ cable lines in rural areas. (IOP conference Series: Materials science and Engineering. Betnam)

14. Berdishev. A., Eshpulatov. N., Matchonov. O., Yusupov. SH. Methodology for conducting an optimization experiment for harvesting dry short-stalked grain crops. 
(1st International Conference on Energetics, Civil and Agricultural Engineering), (2020).

15. Berdishev. A., Djumaboyeva. Z. Evaluation of the effectiveness of electromagnetic treatment of well water. E3S Web of Conferences 209, 07016 (2020).

16. Taslimov. A.D., Berdishev. A.S., Rakhimov. F.M., Yuldashev. A.A. Economic load intervals for selecting $10 \mathrm{kv}$ cable cross-sections for agricultural consumers. International Scientific. (Construction Mechanics, Hydraulics and water resources Engeneering (Conmechydro -2020) Uzbekistan) IOP Conf. Series: Materials Science and Engineering 883 012102. (2020).

17. Rakhmonov. I., Berdishev. A., Khusanov. B., Khaliknazarov. U., Utegenov. U. General characteristics of networks and features of electricity consumers in rural areas Construction Mechanics, Hydraulics and water resources Engeneering (Conmechydro -2020) IOP Conf. Series: Materials Science and Engineering 883012102 (2020).

18. Rakhmonov. I., Berdishev. A., Niyozov. N., Muratov. A and Khaliknazarov. U. Development of a scheme for generating the predicted value of specific electricity consumption (Construction Mechanics, Hydraulics and water resources Engeneering (Conmechydro -2020) IOP Conf. Series: Materials Science and Engineering 883 012102. (2020).

19. Taslimov. A.D., Berdishev. A.S., Rakhimov. F.M., Yuldashev. A.A. Optimal tendency of selecting cable cross-sections for agricultural electrical networks (Journal of Physics: Conference Series USA) Journal of Physics: Conference Series 1515 022050. (2020).

20. Isakov A., Rakhmatov A., Ismailova Z. Study the effect of the design of discharge electrodes on the characteristics of the corona discharge. IOP Conf. Ser.: Earth and Environmental Science 614(1) 012011. (2020).

21. Mirzabaev A., Isakov A., Mirzabekov S., Makhkamov T., Kodirov D. Problems of integration of the photovoltaic power stations with the grid systems. IOP Conf. Ser.: Earth and Environmental Science 614(1) 012016. (2020).

22. Muzafarov S., Balitskiy V., Toqaev B., Batirova L., Isakov A. The research results of cleaning air stream process from aerosol particles in electric fields of corona discharge stream form. IOP Conf. Ser.: Earth and Environmental Science 614(1) 012008. (2020).

23. Isakov A., Mirzabaev A., Sitdikov O., Makhkamova M., Kodirov D. Innovative methods of developing solar power systems for remote and agricultural facilities in Uzbekistan. 2020 IOP Conf. Ser.: Earth and Environmental Science

24. Isakov A., Rakhmatov A. Control over parameters of ionized air. IOP Conf. Ser.: Mater. Sci. Eng. 883(1) 012118. (2020). 